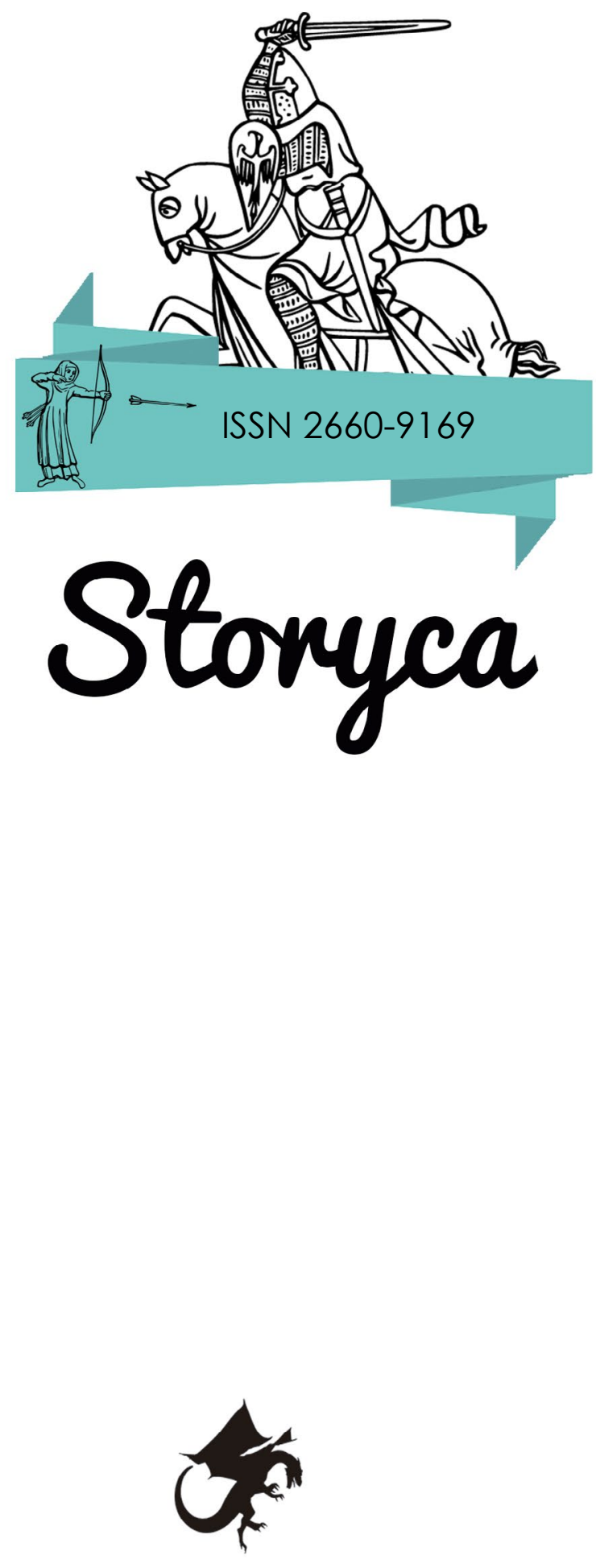

\title{
Del párrafo a la viñeta: El Cid (2020), de José Luis Corral y Alberto Valero
}

\author{
Raquel Crespo-Vila \\ Instituto Politécnico de Bragança
}

La apropiación cristiana del libro como símbolo teológico abrió nuevos caminos decorativos. Las palabras mismas se convirtieron en formas ornamentales [...]. El trabajo se especializó: el escriba solía dejar indicaciones precisas y reservaba los espacios destinados a las ilustraciones; a continuación, los pergaminos se entregaban a miniaturistas e iluminadores. Ya en el siglo XIII, los espacios de la página habían adquirido una condición selvática, compleja y utópica. Allí tiene su origen marginal el cómic. Literalmente: las primeras tiras ilustradas de la historia aparecieron en los márgenes de aquellos antiguos manuscritos. En torno a las letras, surgieron en las páginas increíbles encajes de dragones, serpientes y plantas trepadoras que se enlazaban y se entrecruzaban con una gran riqueza de formas retorcidas. Se poblaron de seres humanos, animales, paisajes, escenas vivaces desarrolladas en series de dibujos. Las pequeñas ilustraciones tenían un marco de orlas vegetales - de ahí deriva el término «viñeta», porque franjas de hojas de vid bordeaban cada recuadro-. Desde la época medieval gótica, de las bocas de los personajes emergen unas pequeñas cintas con las frases pronunciadas, antecedentes de los bocadillos de nuestras historietas infantiles.

Irene Vallejo, El infinito en un junco

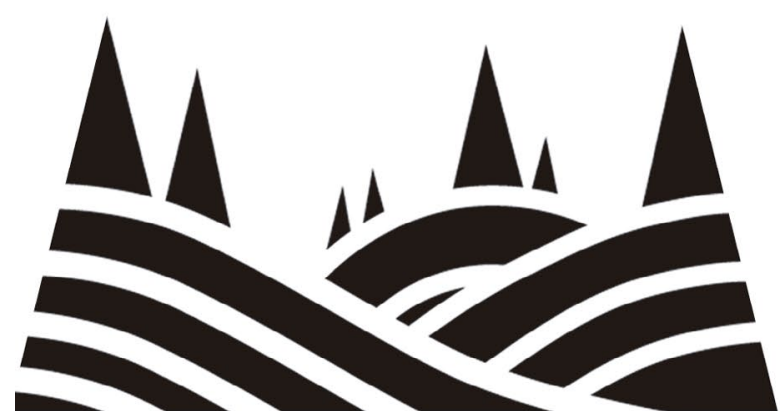




\section{Más allá de la Edad Media y más allá de la literatura}

Ya en la pasada década de los noventa, Christoph Rodiek (1990/1995) hacía balance de la longeva andadura de Rodrigo Díaz de Vivar a través de los siglos y, en su profuso y detallado estudio acerca de la proyección y la recepción internacional de la materia cidiana -o del "esquema argumental recurrente del Cid», en la etiqueta del propio crítico-, daba cuenta de la enorme capacidad de la fábula del Cid para adaptarse no solo a distintos contextos históricos y geográficos, sino también a lenguajes o medios narrativos muy dispares - que, en el caso concreto del siglo XX, sirvieron para marcar un determinado espíritu cultural- No en vano, y como bien apuntaba el mismo Rodiek, convertida en contenido de carácter transversal, la materia cidiana se aclimata «al "mercado" de historias prometedoras» (1995: 419). O dicho de otro modo: al paradigma de la llamada uindustria cultural» o de la «cultura de masas» (para un repaso de esta etiqueta véase, por ejemplo, Abruzzese, 2004); pues, una vez superado el ecuador del siglo pasado, la fábula del Cid hubo de extenderse a formatos novedosos, de naturaleza más popular si se quiere, como el cine o el cómic (Rodiek, 1995: 379-396; 404-408; Aguilar, 2014).

Lejos de languidecer y contraerse, este fenómeno de expansión mediática de la materia cidiana parece haberse acentuado con la llegada del siglo XXI. Un caso evidente a este respecto es el que atañe, por ejemplo, al ámbito audiovisual. Dado el salto a la gran pantalla en 1961, con la película dirigida por Anthony Mann y reencarnado el héroe en Charlton Heston, el Cid tomaba el rostro del actor Jaime Lorente en 2020, en la serie de ficción escrita por Luis Arraz y Adolfo Martínez, producida por el grupo Zebra y distribuida por la plataforma Amazon Prime Video. Sin olvidar tampoco aquel Campeador interpretado por Ángel Cristo en la curiosa propuesta fílmica de Angelino Fons - El Cid cabreador (1983) —; ni aquella serie infantil emitida por TVE en 1980, Ruy, el pequeño Cid (RBA Internacional y Nippon Animation), o, en fin, el largometraje dirigido por José Pozo, El Cid, la leyenda (Filmax, 2003), que confirman la incursión del caballero en el terreno de la animación.

Igualmente, la investigación de Prieto Marugán (2007) arrojaba datos concluyentes acerca de la presencia del héroe en la esfera de la música: más de ochenta composiciones de distinta naturaleza y época ratifican que la materia cidiana es musicable. Más específico y reciente es, por lo demás, el catálogo elaborado por Boix Jovaní (2015), implementado posteriormente por Saguar García (2017) y centrado en la pervivencia y transmisión del mito cidiano a través de las letras del heavy metal. O el concierto para coro, órgano y nuevos medios Campeador, compuesto por Carlos Miguel Fernández Soto — también conocido por el pseudónimo lazabo_, publicado en 2018 y relanzado, con nuevos temas, en 2020.'

Tampoco se ha desaprovechado el potencial de la figura cidiana en formatos actuales más lúdicos. He ahí la aparición del Campeador en el argumento

\footnotetext{
1. Para ampliar esta información, remito al sitio web del compositor, desde donde se puede acceder a las piezas del concierto: http://www.iazabo.com/ (última consulta: 24/12/2021).
} 
de un conjunto de videojuegos que Escandell Montiel (2017) sumariaba y examinaba. O la publicación, más analógica, de Reconquista (Edge Entertainment) en el año 2018; un juego de mesa ideado por Marco Antonio del Campo cuyo argumento intenta recrear los continuos enfrentamientos entre cristianos y musulmanes durante el siglo XI peninsular. Por ello, como en la historia, el Cid se convierte aquí en personaje estratégico, capaz de modificar las reglas del juego. ${ }^{2}$

Y, en fin, el caso que aquí más interesa y que habrá de ocupar los epígrafes que siguen: el del cómic. Porque también ha logrado acomodarse la materia cidiana al lenguaje de las viñetas y a una forma narrativa que - híbrida, mestiza, deudora clara de la "cultura de masas» y desconsiderada por el canon cultural durante décadas - recibe ahora, gracias al esfuerzo de los historietistas y en buena medida, según Santiago García, a la aparición de esa forma particular llamada «novela gráfica», reconocimiento y atención por parte de la crítica (passim García, 2010).

Así, en tanto que jalón singular de la proyección del héroe sobre el amplio espectro cultural contemporáneo, valía la pena dedicar unas líneas a la novela gráfica cidiana aparecida en el año 2020 -Ediciones B-, titulada El Cid, guionizada e ilustrada por Alberto Valero y basada en la novela histórica homónima de José Luis Corral (2000); y examinar, pues, esta nueva recreación de la materia cidiana en su relación con el texto literario del que parte $-\mathrm{y}$ aun con una larga tradición debida al caballero- y en función de ciertas particularidades icono-textuales que atañen a la novela gráfica.

No obstante, y como ya demostraron otros estudios (Rodiek, 1995; Aguilar, 2014 ; también Beck, 2019), la propuesta de José Luis Corral y Alberto Valero no es el primer ejercicio de representación gráfica del Cid, ni tampoco el primer trasvase de la historia de Rodrigo Díaz de Vivar al lenguaje concreto de las viñetas, las didascalias y los bocadillos.

\section{Los antecedentes}

A medio camino entre lo verbal y lo visual, la creación historietista ha sido un nicho fecundo para la actualización de motivos medievales; bien como fundamento argumental -recuperando episodios históricos reales, documentados-, bien como telón de fondo -lleno, en muchos casos, de ucronías y anacronías-, el Medievo ha sido escenario recurrente para desarrollar la acción de muchas historias comicográficas (Gallo León y Játiva Morales, 2009). Personajes tan populares como El príncipe Valiente, creado en 1937 por Harold Foster (Canadá), o celebridades del tebeo español, como El guerrero del antifaz (Manuel Gago García, 1944) y El capitán Trueno (Víctor

2. Tal y como se explica del sitio web de la compañía editorial Edge Entertainment, de donde extraigo la información: «Los más aficionados a la historia disfrutarán una regla opcional que introduce el juego, El destierro del Cid. Esta regla modifica la partida para una experiencia que refleje los cambios de bando en los que Rodrigo Díaz de Vivar, El Cid Campeador, se vio envuelto durante la contienda del siglo XI españolı. En: http://bit.ly/2mafmmb (Consultado el 20/12/2021). 
Mora Pujadas y Manuel A. Zaragoza, 1956) dan cuenta, efectivamente, de la longevidad y el éxito de ese maridaje entre Edad Media y viñeta.

Son muchas las analogías que se podrían establecer entre los protagonistas de aquellas historietas españolas y la propia figura cidiana; nótese, sin ir más lejos, el carácter conservador y panfletario que la coyuntura ideológica de la España franquista imprimió sobre ellos (véase, a este respecto, Lacarra, 1980; Peña Pérez, 2010; Heusch, 2017). Sin embargo, la fábula cidiana no escapó a la creatividad del noveno arte y el Campeador acabaría protagonizando su propia colección de viñetas, fuera incluso de nuestras fronteras.

Dietris Aguilar (2014) nos recuerda, por ejemplo, el caso de El poema del ciD canpeadoR sintéticamente abreviado para todos, de Oski y César Bruto; una historieta argentina de 1957 que, al decir de la misma autora, constituye «una versión paródica» del texto clásico al que se refiere y donde la figura del Cid se presenta ciertamente alejada de la que protagoniza aquella composición:

No hay intención de retratar a nuestro héroe sino de «versionarlo» con fines humorísticos. De hecho, sólo se muestra más su aspecto guerrero, antes que el de esposo, de vasallo o de padre. Oski y César Bruto sabían claramente cuál era el horizonte de expectativas de sus receptores: un grupo de lectores cultos, que disfrutaban en clave humorística del «analfabetismo gráfico» y textual de una obra en la que subyace una mirada entre socarrona y cáustica (Aguilar, 2014).

Ya en nuestro país, con talente completamente distinto, surgía de la mano del historietista Antonio Hernández Palacios la serie El Cid, que, publicada

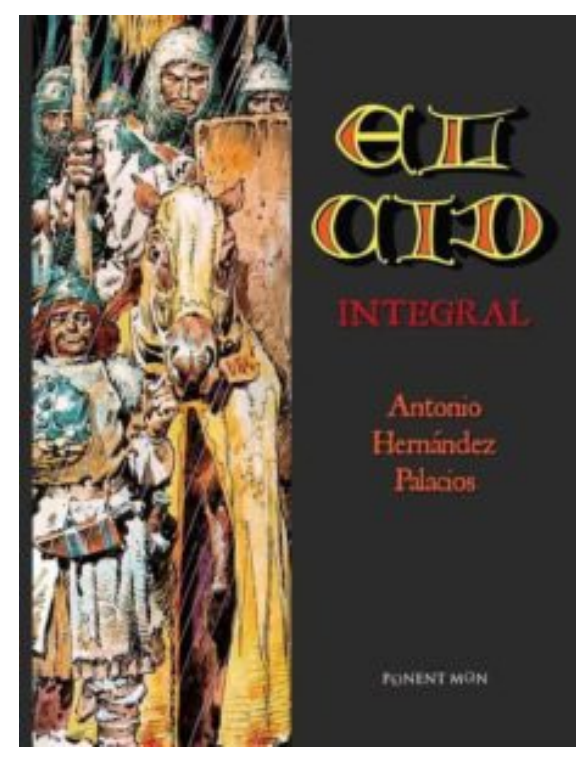

El Cid, Hernández Palacios entre la década de los setenta y los ochenta, se compone de cuatro tomos: el «Libro I. Sancho de Castilla» y el «Libro II. Las Cortes de León», seriados entre 1971 y 1972 por la revista Trinca (Editorial Doncel); el «Libro III. La toma de Coimbra», que veía la luz en 1982, gracias Ikusager Ediciones que también reeditaría los dos anteriores-; y, en fin, el «Libro IV. La Cruzada de Barbastro», de 1984 y, lamentablemente, inconclusa (Uriondo, en Hernández Palacios, 2015: 5).

Si bien el proyecto de Hernández Palacios pretendía una extensión mayor, el argumento de la serie publicada abarca un arco muy breve de toda la acción que se podría desarrollar a propósito de la materia cidiana, sea en la versión más realista de la historia del Campeador o en la más legendaria. Así, arrancando en el año 1063, consumada la batalla de Graus, la serie se extiende hasta la muerte del rey Fernando I de León, Castilla y Galicia, en 1065; fecha clave esta última en la biografía cidiana fielmente documentada. Pues, una vez repartido el reinado de Fernando I entre sus tres hijos varones, el caballero de Vivar se convertiría en 
alférez real de Sancho Il de Castilla, para más tarde verse envuelto en la «guerra fratricida» que, grosso modo, enfrentaría al monarca castellano con Alfonso $\mathrm{VI}$ de León y terminaría con la muerte de aquel en 1072, durante el «Cerco de Zamora» (Fletcher, 1989). Por todo ello, no es casual que, en sus primeros pasos, la propuesta de Hernández Palacios ceda un mayor protagonismo al personaje de Sancho II de Castilla que a la propia figura del Cid Campeador (Uriondo, en Hernández Palacios, 2015: 3-4).

Entre las bondades de la obra de Hernández Palacios, Rodiek (1995: 404408) apuntaba la deuda del cómic con un referente de los estudios cidianos como La España del Cid (1929), de Menéndez Pidal, ampliando, eso sí, lo documental con lo anecdótico, para adaptar la investigación pidaliana a las características propias del cómic como medio narrativo. Así, a pesar de que Hernández Palacios no consiguió plasmar toda la erudición contenida en su fuente y de que, en ocasiones, se desmarcó de ella, el mismo crítico reconocía «que los conocimientos de Menéndez Pidal difícilmente pueden ser transmitidos a un público moderno de masas de forma más entretenida -es decir, eficaz- que con bloques textuales amarillos y secuencias de imágenes a todo colorn (Rodiek, 1995: 408).

Todo ello interesa aquí, porque, en tanto que hito cidiano de la viñeta, El Cid de Hernández Palacios constituye un antecedente directo del caso que atañe a este trabajo y revela su importancia en el hecho de que, en el año 2015, la editorial Ponent Mon haya lanzado al mercado una edición íntegra de la serie - El Cid. Integral-; un cuidado volumen de más de doscientas páginas que, además, recoge el borrador del trabajo y la reproducción gráfica de los manuscritos del autor.

En última instancia, no debe pasar sin mención en este epígrafe otro tipo de proyectos; como el emprendido desde Cascaborra Ediciones -con Julián Olivares Dengraalacabeza-que, habiendoadquirido los derechos de Caliber Cómics (Estados Unidos) por El Cid — dibujado por Waine Reid y guionizado por Gary Reed- reeditaría este cómic americano para publicarlo ahora en español (2018), como el sexto número de su colección "Historia de España en viñetas».3. O, más allá de la reedición, a propuesta -

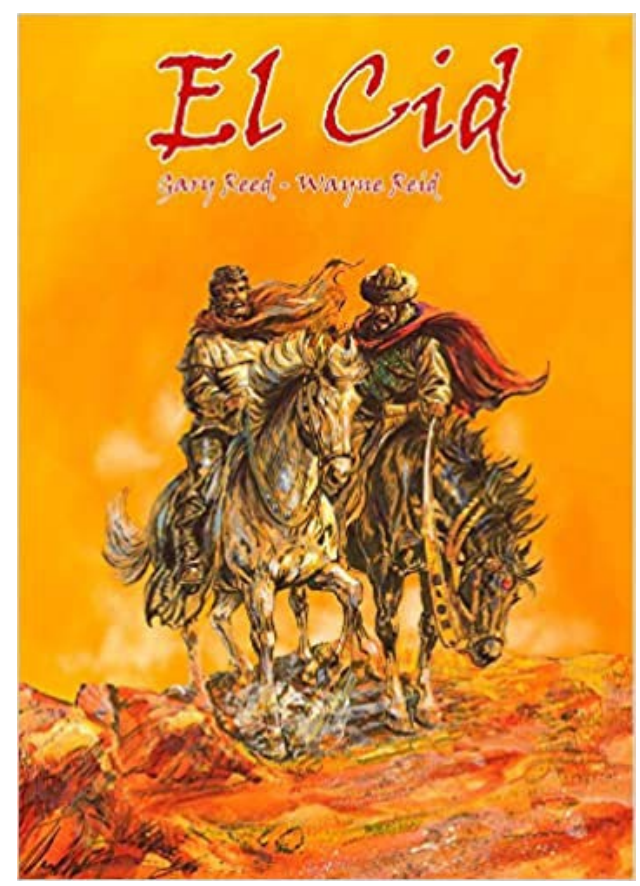

El Cid, Reid y Reed

3. La singularidad de la propuesta radica en la estrategia económica del proyecto, puesto que, con el apoyo del grupo Verkami, la editorial puso en marcha una campaña crowdfunding para financiar de manera colectiva la reedición de este cómic; una campaña que, a golpe de retórico eslogan — «Qué buen vasallo sería si tuviera un buen señor... Y qué buen cómic será con buenos mecenas que nos ayuden a financiarlo»-, conseguía recaudar los fondos necesarios para cubrir gastos de traducción, maquetación e imprenta, facilitando así que El Cid viera la luz en 2018. Para más información sobre el proyecto y sus índices de recaudación, así como para la visualización del vídeo promocional de la campaña, se puede visitar la plataforma del grupo Verkami, en la siguiente dirección electrónica: http://bit. ly/2mHPEłB (Consultado el 14/12/2021). 


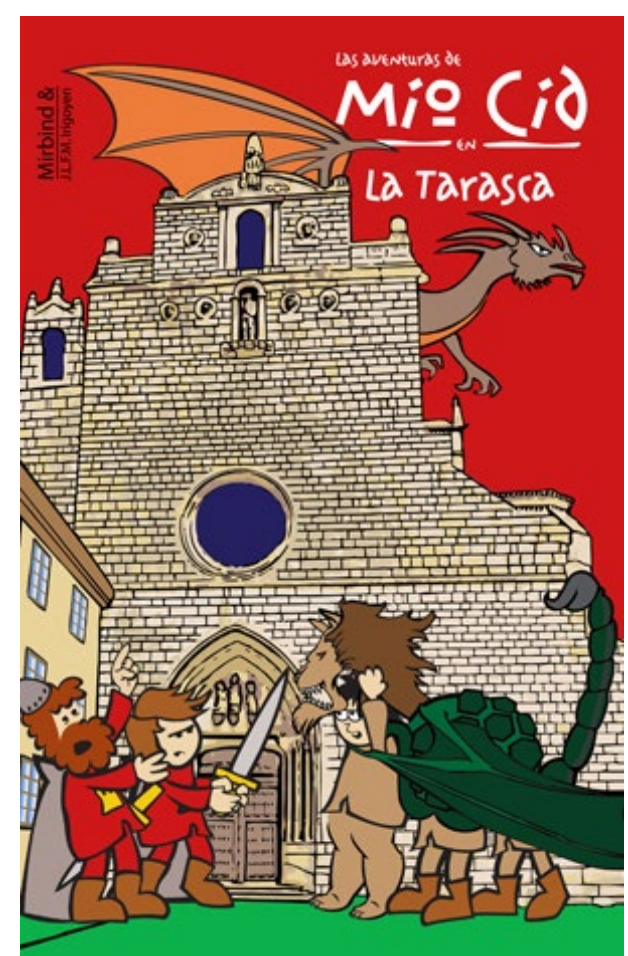

Las aventuras de Mio Cid, Mirbind

también mencionada por Beck (2019: 164)— del dibujante "Mirbind". Dirigida a un público juvenil, esta cuenta con dos números: «La estatua del buen Conden, que abría la serie en 2009 y presentaba a parte de los personajes más importantes de la temática cidiana -el rey Sancho II, el rey Alfonso Vl, Álvar Fáñez y también Bellido Dolfos; inmiscuidos en la búsqueda de un tesoro-; y el segundo, que aparecía en el año 2011 bajo el título de «La Tarasca» -nombre del dragón que Rodrigo Díaz debe enfrentar-.

\section{El Cid (2000) de Corral}

El Cid de José Luis Corral y Alberto Valero parte -ya se ha dicho- de la

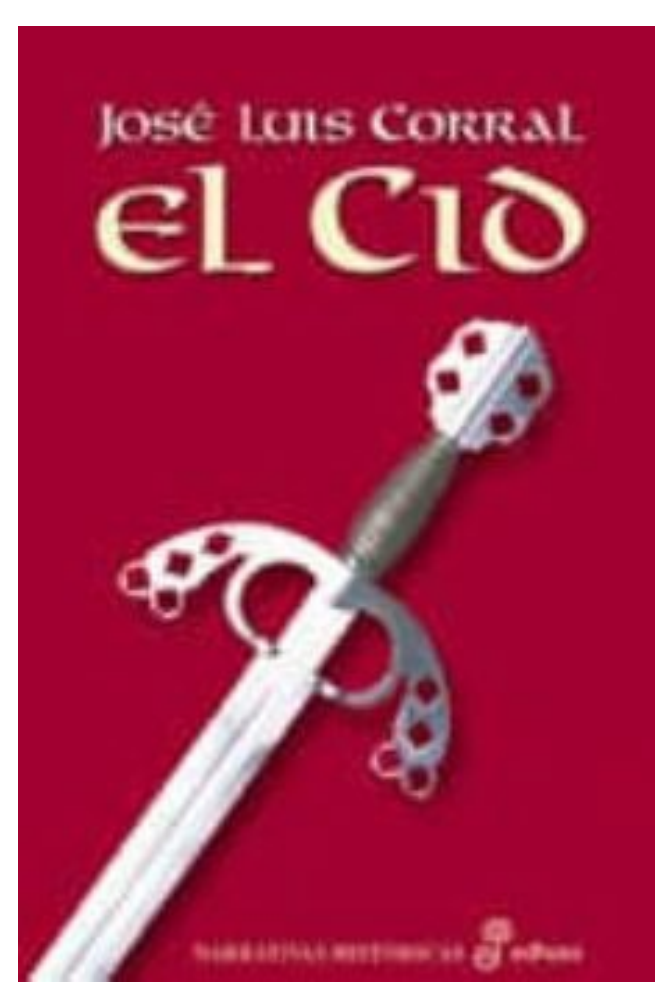

El Cid, José Luis Corral novela publicada veinte años antes por el primero, medievalista y uno de los narradores más reconocidos del género histórico en el panorama español actual. Inscrita en ese fenómeno de «eclosión» medieval que autores como Gómez Redondo (1990), Díez de Revenga (1993), Yerro Villanueva (2001), Ruiz-Domènec (2009) y Huertas Morales (2015) notaron para el caso de la narrativa española de finales y principios de siglo, la novela de Corral - que ya fue tratada en otro lugar (Crespo-Vila, 2018)- reconstruye la biografía de Rodrigo Díaz de Vivar desde el respeto y el rigor historiográficos.

Fiel, por tanto, a las fuentes medievales que, en efecto, documentan la existencia de este caballero, el novelista recorre allí los episodios más importantes de la trayectoria vital de Rodrigo Díaz, cubriendo un arco temporal que arranca en el año 1063 con la batalla de Graus- y concluye con la 
muerte del Campeador en la ciudad de Valencia, en el año 1099; pasando por episodios cidianos de consideración histórica (véase, a este respecto, Fletcher, 1989) como el Cerco de Zamora de 1072 (Corral, 2001: 124-136), el enfrentamiento en Cabra entre las tropas del Cid y las de García Ordóñez (2001: 181-202) -y posible antecedente del primer destierro-, los dos destierros del Campeador (2001: 214 y ss.; 2001: 408-415) o la conquista de Valencia (1093-1094) en toda su crudeza; sin olvidar, además, los años que el caballero pasó en la taifa zaragozana al servicio de gobernantes musulmanes, una vez desterrado en 1081.

Así, el texto de Corral encaja dentro de esa categoría de «historia novelada» que, en su taxonomía acerca de la novela española contemporánea de tema medieval, proponía Huertas Morales (2015: 81-118); esto es: textos con mínima injerencia de la inventiva, en los que se persigue la reconstrucción fidedigna del pasado histórico, amenizados a través de pequeñas dosis de ficción y muy cercanos, por tanto, al ámbito de la divulgación y del ensayo históricos. El componente ficcional de esta obra se reduce, prácticamente, a la inclusión del personaje de don Diego de Ubierna, que, caracterizado como caballero del Cid, se convierte en narrador autodiegético del relato y acentúa esa impresión de veracidad de la novela al revelarse como testigo ocular de los hechos más relevantes de la biografía cidiana.

La intención de verismo es tal que el propio Corral declara las fuentes documentales manejadas para la redacción de la novela en una «Nota del autons incluida al final del volumen. Sin embargo, tal nota menciona también el Cantar de mío Cid -CMC en adelante-, utilizado, eso sí, "con cierto cuidadoı (2001: 568). No en vano, y a pesar de la evidente y marcada inclinación de la recreación cidiana de Corral hacia el archivo histórico, lo cierto es que también se pueden rastrear en la novela ciertas referencias a la tradición puramente literaria relacionada con el Campeador. Nótese, por ejemplo, el guiño hecho en la novela (2001: 225-226) al motivo del engaño a los judíos contenido en el CMC (vv. 78 y 213) - y que, en términos generales, la crítica ha dado por ficticio (Salvador Miguel, 1977:207)—. O la clara alusión en el siguiente fragmento a los versos 40-48 del CMC, donde una uniña de nuef añosı burgalesa advertía al héroe de las órdenes del monarca:

Unos pocos nos dirigimos hacia la catedral de Santa María, donde Rodrigo quería rezar antes de partir. En la plaza, delante de la portada de figuras esculpidas en piedra, una niña se acercó hasta Rodrigo.

- ¿̇Tú eres el Campeador? -le preguntó.

- Sí, por ese apodo me conocen algunos —respondió Rodrigo.

- Mi madre me ha dicho que el rey no quiere que vivas en Castilla, y que quien te ayude perderá su casa y sus ojos.

-En ese caso, obedece a tu madre.

La madre de la niña apareció en la plaza y la cogió de la mano llevándosela de allí en volandas (Corral, 2001: 223-224).

Cumpliendo, pues, con aquel desiderátum narrativo que Rodiek (1995: 412) esgrimía en las conclusiones de su estudio sobre la proyección de la 
materia cidiana $-y$ que requería la aparición de una novela cidiana fiel a la historiografía-, gracias a la reconstrucción de la biografía cidiana desde la documentación, la novela de Corral constituye, por un lado, un ejercicio de "corrección histórica» a propósito de esa imagen idealizada del héroe, alimentada durante siglos y, presumiblemente, anclada todavía hoy en el imaginario colectivo. Lejos del maniqueísmo, humanizado, el Cid de Corral escapa, por lo demás, a esa estampa de vasallo resignado y estridente defensor de la cristiandad, que, a decir verdad -y desde lo planteado por la crítica al respecto (Spitzer, 1962: 19; Catalán, 2000; Montaner, 2007)—, tampoco cabría colegir de la lectura del CMC.

Por otro lado, y atendiendo a esas sutiles alusiones a todo el aparataje literario inmiscuido en la mitificación de la figura cidiana - que, en ocasiones, el narrador de la novela parece querer desmentir: «Juglares, trovadores y cronistas cantan [...] las hazañas del Cid y ensalzan su figura; algunos inventan cosas que jamás ocurrieron y otros describen al Campeador de manera muy distinta a como realmente era») (Corral, 2001: 564)-, El Cid de Corral adquiere también trazas de «lección» o «glosa» literaria, invitando al lector a reconsiderar una relectura de los textos clásicos.

Desde esta perspectiva, y como ya se hubo de notar en aquel trabajo anterior (Crespo-Vila, 2018:37), El Cid de Corral responde a ese afán divulgativo que, manifestándose de manera singular en la novelística contemporánea de asunto medieval, es connatural al género de la novela histórica; género que ha asimilado, por lo demás y quizás como ningún otro, las ligaduras del mercado editorial actual —sigo de nuevo a Huertas Morales (2015: 39-44) —; o los parámetros, si se quiere, de esa sindustria culturalı, que, entre otras cosas, ha erradicado las tradicionales fronteras que separaban la erudición del consumo masivo y ha revalorizado modelos y lenguajes narrativos anteriormente considerados «menores».

\section{El Cid (2020) de Corral y Valero}

Cabría, en primer lugar, definir la propuesta de Corral y Valero desde la etiqueta de uso común que podría resultar más adecuada para el caso: «novela gráfica»; si bien es cierto que, como advierte Santiago García (2010) -quien examinó con detalle los orígenes de tal noción-, tal marbete no es de agrado generalizado y plantea ciertas dudas en el ámbito de la ilustración. En la propia explicación del autor:

Por supuesto, «novela gráfica» es sólo un término convencional que, como suele ocurrir, puede llamar a engaño, pues no hay que entender que con el mismo nos referimos a un cómic con características formales o narrativas de novela literaria, ni tampoco a un formato determinado, sino, sencillamente, a un tipo de cómic adulto moderno que reclama lecturas y actitudes distintas del cómic de consumo tradicional (García, 2010:15-16). 
Tomaré, en cualquier caso, dicho marbete para referir El Cid de Corral y Valero y diferenciarlo de otras obras cidianas ilustradas, como la de Hernández Palacios, que, frente al texto que me ocupa, se publicó de manera seriada, secuenciada. No así, El Cid más actual, cuyas páginas vieron la luz de manera íntegra, como un todo orgánico, concluso y preparado a la luz de un texto precedente.

En este sentido, convendría igualmente calificar la propuesta de Corral y Valero en su relación con la novela fuente de la que parte. Opto, para ello, por el término de ureescritura» frente al de «adaptación», taly como planteaba, tras una concienzuda revisión conceptual, Gutiérrez García-Huidobro (2014) para caso de

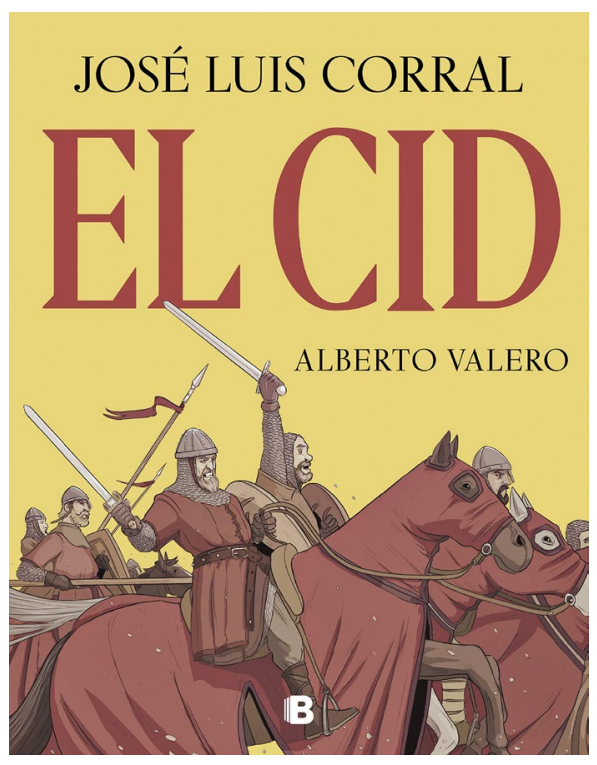

El Cid, Corral y Valero similar naturaleza al que atañe a estas páginas; esto es, un transvase narrativo dado desde los párrafos a las viñetas:

\begin{abstract}
Si se entiende el cómic desde su estatus de híbrido por medio de su tensión entre texto y lenguaje, tal como lo expresa toda la tradición teórica del medio, entonces podría plantearse que el cómic, por sus particularidades narrativas y formales, puede producir adaptaciones de textos literarios que proyecten muchos aspectos inusitados de sus fuentes a niveles de lectura e interpretación. Es decir, que las adaptaciones más que copias son reescrituras de su fuente en la clave del medio en que se está elaborando la nueva versión (Gutiérrez García-Huidobro, 2014: 193).
\end{abstract}

Desde tal perspectiva y considerando la dualidad expresiva e icónico-textual que concierne al medio, es posible señalar una serie de aspectos discursivos que, frente al texto fuente de Corral, parecen ponderarse, desarrollarse 0 ampliarse en la propuesta ilustrada posterior.

Por el contrario, la fábula —es decir, la historia propiamente dicha y relatada en El Cid de Corral y Valero- se mantiene fiel con respecto a la novela original, de la que parafrasea fragmentos, insertados ahora en globos y didascalias. Lejos de aquella "amplificación parásita» de motivos que Rodiek (1995: 404) percibió en el cómic de Hernández Palacios con respecto al «esquema argumental recurrente del Cid», lo cierto es que la propuesta ilustrada de Corral y Valero sigue de cerca la acción contenida en su texto fuente, e igualmente comprende los hechos más relevantes de la biografía cidiana desde el año 1063 hasta la fecha de su muerte, en 1099. Aunque - valga apuntarlo-, a diferencia de la novela de Corral, estructurada en veinticuatro capítulos, en la novela gráfica actual la historia de Rodrigo Díaz de Vivar se organiza de manera tripartita, y en función de los más importantes escenarios en los que se hubo de desarrollar. Así rezan los carteles que encabezan cada parte: «Parte I: Castilla», «Parte II: Zaragoza», «Parte III: Valencia». 
El Cid ilustrado reduce, por lo demás y considerablemente, su extensión con respecto al texto originario de Corral; hecho este debido, en gran parte y como apunta Rubén Varillas, a la singular «simultaneidad» expositiva del medio comicográfico frente al literario:

Parece evidente que, en la literatura, la modalidad descriptiva complementa la narración a expensas de la evolución de la historia. Cuando un escritor describe un lugar o un personaje, por norma, la narración se detiene. En el cómic esto no es necesario, ya que la descripción de personajes y escenarios es visual y, casi siempre, simultánea al desarrollo de la acción (Varillas, 2009: 75).

Así, pues, la versión ilustrada de El Cid, en un primer momento, parece «decantar» la historia primigenia de Corral, seleccionado solamente la acción del relato en detrimento de aquellas partes más descriptivas. Sin embargo, la descripción sigue presente en la novela gráfica, aunque codificada allí de manera visual, a través de las estampas de Valero. De hecho, y como bien notaba Varillas (2009: 75), no es infrecuente, en la retórica de las viñetas, la inclusión de pasajes puramente descriptivos -y acompañados de exiguas didascalias- que identifican el escenario y localizan la acción, o que presentan objetivamente a sus protagonistas. He ahí el panel que abre El Cid de Corral y Valero, por ejemplo, y que muestra el monasterio de San Pedro de Cardeña en el que se educaba como clérigo Diego de Ubierna. El panel -al igual que otras y numerosas viñetas que, en la novela gráfica, descubren castillos, fortificaciones y palacios medievales-, si bien incluye información de carácter narrativo - a través de los carteles-, igualmente describe una determinada localización espacio temporal y ayuda al lector a situar la historia en un ambiente específico específico. Y, en este mismo sentido descriptivo, se puede señalar la viñeta que, en la segunda página de la novela gráfica y ya exenta de didascalias, presenta por primera vez ante el lector -mediante un plano medio, objetivo- el rostro de Diego de Ubierna.
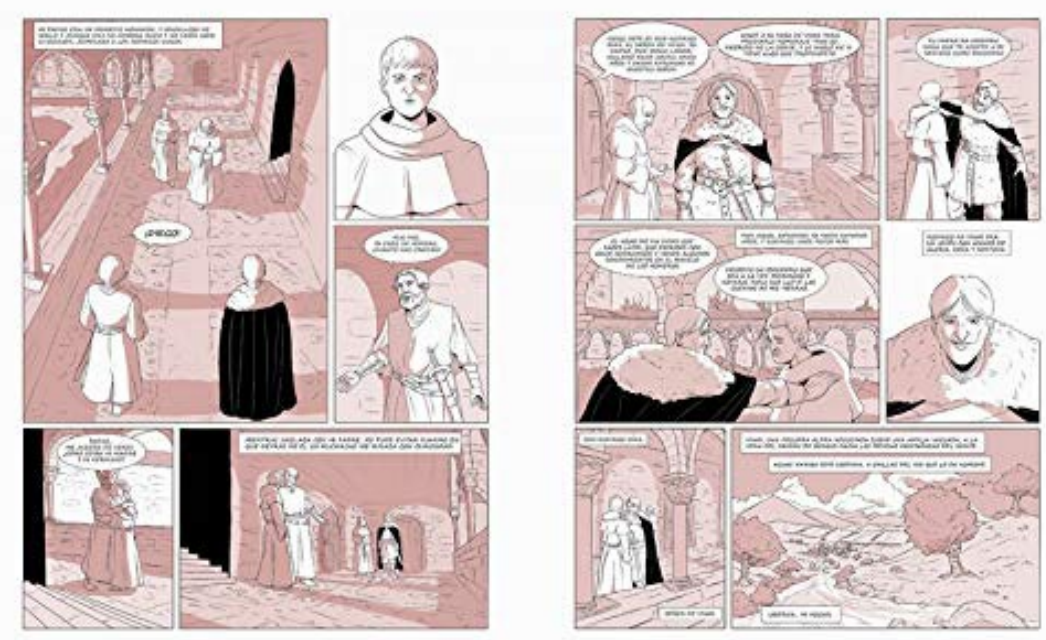
No obstante, aquella estampa de Diego de Ubierna también interesa porque, a partir de ella, se puede subrayar un aspecto técnico-estilístico que, a mi entender, viene a revelar otro punto de encuentro entre novela y novela gráfica: la verosimilitud y la intención verista. Nótese que, lejos de la caricatura o el esquematismo - de nuevo sigo aquí a Varillas y sus apuntes sobre el lenguaje del cómic (2009: 57) - las ilustraciones de Valero se sitúan en el plano del realismo. Y al igual que el texto de Corral, los dibujos de la novela gráfica recrean la historia real, así documentada por la historiografía, de Rodrigo Díaz de Vivar; una figura muy concreta de la historia medieval castellana y, por lo mismo, de rasgos definidos y detallados en la propuesta visual de Corral y Valero - adviértase, por ejemplo, la cicatriz que cruza la cara del Campeador en su representación gráfica-. Si el propósito de la novela de Corral era, pues, la corrección histórica, la mímesis visual seleccionada por Valero para sus estampas en la novela gráfica posterior parece contribuir a ello.

En dirección similar podría interpretarse - creo-la sobriedad del cromatismo escogido por el ilustrador, limitado este a una paleta de colores que incluye el negro, el blanco y una variada gama de rosados. Tal solución contrasta, por ejemplo, con el exuberante espectro cromático utilizado en su día por Hernández Palacios en su serie cidiana -y más cercano al estilo del cómic de superhéroes o de ciencia ficción-. Y, aunque paradójico - puesto que la realidad la percibimos «a todo colon», dicha exigüidad cromática de la novela gráfica parece responder al mismo afán histórico y, sobre todo, divulgativo del texto original: dando impresión cálida los rosados y, según la convención general del color, generando una atmósfera estimulante (Cuñarro y Finol, 2013: 283-284) — porque al fin y al cabo, se trata del Cid Campeador-, la coloración de las viñetas no despista más de lo necesario la atención del lector hacia lo allí descrito o narrado.

Esa intención divulgativa, común entre novela y novela gráfica, es quizás más evidente si se consideran determinadas soluciones tomadas por el ilustrador, ya no en el plano de la historia, si no en el ámbito puramente discursivo. Creo que especialmente significativa -no solo a este respecto, sino también en lo que se refiere a la simultaneidad expresiva y, por tanto, a las posibilidades narrativas del medio ilustrado- es la solución tomada por Valero para trasladar a la novela gráfica la profusa explicación de Al-Mutamin acerca de la situación política exterior de la taifa de Zaragoza, una vez que el Cid se pone a su servicio tras el primer destierro y ha de encarar su primera misión.

En un largo párrafo de la novela, Corral (2001:248-249) enumeraba, en boca del rey musulmán, todas las amenazas que comprometían la estabilidad de Zaragoza. Con maestría y sin pérdida de información, el párrafo se traduce en la novela gráfica mediante un solo panel organizado a modo de esquema $o$ diagrama, en el que, distribuidas espacialmente, quedan representadas las diferentes amenazas externas de la taifa a través del rostro de sus principales responsables: el rey de Aragón, en el norte; los condes de Barcelona, en el este; el soberano de Albarracín, en el sur; y, en fin, Alfonso VI, el monarca cristiano, en el oeste. 
Asimismo -y en tanto que fue mencionado en líneas precedentes y no desaprovechado por la versión gráfica-, vale la pena destacar la solución escogida para la «traducción» del lance de aquella niña de nueve años que, según la tradición literaria —según el CMC - se acerca al Campeador en la ciudad de Burgos. Tal motivo, de naturaleza ficcional, consigue subrayar su simbolismo - cifrado en la contraposición entre la imagen de la dulce niña frente a la del aguerrido caballero- en el caso de la novela gráfica, gracias a recursos propios del lenguaje ilustrado. En la observación de Varillas:

\begin{abstract}
El cómic [...] permite la omisión del escenario como recurso que centrará la atención del lector sobre otros aspectos de la narración (normalmente sobre los personajes, como en este caso). En estos casos, los márgenes mismos de la página o la viñeta se convierten en el único soporte contextual de la acción. Lo más frecuente es que este recurso funcione como mecanismo focalizador para destacar un gesto, un rostro o un elemento de la historia [...] (2009: 86).
\end{abstract}

Así, pues, en un panel no limitado por las líneas de la viñeta, Valero ilustra la secuencia sobre fondo blanco y, desapareciendo el telón de la ciudad de Burgos tras los personajes, estos reciben toda la atención del lector, que se percatará de una tierna estampa en la que el Campeador aparece acuclillado frente a la niña.

La capacidad de ampliación del lenguaje del cómic se percibe, de igual forma, en otro tipo de elementos discursivos de suma trascendencia; como, por ejemplo, los puntos de vista. Tal y como explica, de nuevo, Rubén Varillas (2009: 123), la naturaleza visual del cómic — de la novela gráfica, en este casopermite la aparición de múltiples perspectivas, en función de los objetivos del autor. Así, si bien existirá siempre una instancia narradora principal y reguladora, una lectura atenta revelará la presencia de puntos de vista diversos en la enunciación. Dejando al margen la variedad que, necesariamente, aporta la contraposición de los distintos tipos de «planos» (Varillas, 2009: 126-152) a lo largo de toda la novela gráfica de Corral y Valero, destaco aquellos que representan la perspectiva subjetiva del Campeador, al perder este el conocimiento una vez herido en Albarracín. Fundidas completamente a negro y acompañadas de textos que trasladan los diálogos - y la desesperaciónde los hombres que lo acompañan en la batalla, tales viñetas dan impresión vívida del desfallecimiento del personaje, desde su propio punto de vista.

Directamente relacionado con el punto de vista, se encontraría, en fin, la cuestión de la voz narrativa que, como se ha dicho, en el caso de la novela de Corral pertenece a Diego de Ubierna. Tal instancia, en primera persona, se mantiene en la novela gráfica, convive allí con los diálogos expuestos en bocadillos y se explicita, sobre todo, a través de las didascalias. Ahora bien, «las posibilidades que ofrece una narración en este sentido son muy numerosası (Varillas, 2009: 152) y, junto a ese narrador, cabría reconocer en la novela gráfica de Corral y Valero otra instancia narrativa -quizás ese «autor implícito» del que habla Varillas (2009: 153) - , menos evidente, pero igualmente presente y configurada a través de las herramientas del propio discurso comicográfico. 
Adviértanse, por ejemplo, los carteles que estructuran y localizan la historia - «Parte I: Castilla», «Parte II:Zaragoza», «Parte III: Valencia»—, cuya enunciación no cabe atribuir al propio Diego de Ubierna, sino a un ente narrativo distinto.

Así, pues, basta este breve repaso por los aspectos más llamativos de $E l$ Cid de Corral y Valero para definirla como ureescritura», y no "adaptación», de la novela histórica de Corral; ya que, aun siguiendo de cerca la obra original y respetando el argumento, el tono y la intención de aquella en la medida de lo posible —lo que, a buen seguro, gustará a muchos lectores-, el trasvase a un nuevo código expresivo, rico y variado en recursos, contribuye a la configuración de un discurso narrativo autónomo y, en ocasiones, enriquecedor y potenciador del relato primigenio.

\section{Coda}

En función de ese afán divulgativo que se ha venido defendiendo para la novela gráfica de Corral y Valero - también para la novela fuente de Corrala lo largo de estas líneas, convendría considerar, en fin -y para un trabajo ulterior-, la potencialidad de la propuesta de estos autores para su uso como recurso didáctico en las aulas, tanto de historia como de literatura. Ya no solo por el enorme arsenal informativo allí contenido a propósito de la época, las figuras y los acontecimientos históricos que configuran el argumento de la obra. Sino porque, como apuntaba lker Saitua, upor otro lado, el cómic, como representación del pasado o producto cultural que se inscribe en un contexto histórico dado, puede servir como fuente de información sobre el momento en el que fue creado» (2018: 78). Desde este planteamiento, más allá de datos y referencias historiográficas, un texto como el El Cid de Corral y Valero, deudor de la cultura visual contemporánea y representativo de la aleación entre erudición y entretenimiento, serviría para plantear, ante estudiantes y lectores, más de un punto de encuentro entre el mundo medieval y el contemporáneo; tal y como ya los hubo de notar Umberto Eco (1996: 82-83) y como, en última instancia, pretende reflejar el largo fragmento de Irene Vallejo (2019: 355-356) escogido para introducir estas líneas. 


\section{Bibliografía}

\section{Fuentes primarias}

Cantar de Mio Cid (2007), edición, prólogo y notas de Alberto Montaner, Estudio preliminar de Francisco Rico, Barcelona, Círculo de LectoresGalaxia Gutenberg.

Corral Lafuente, José Luis (2000/2001), El Cid, Barcelona, Edhasa.

Corral, José Luis y Alberto Valero (2020), El Cid, Barcelona, Ediciones B.

MIRBIND (2009), "La estatua del buen Conder. Colección juvenil Las aventuras de Mío Cid, Autoedición.

MIRBIND (2011), «La Tarasca», Colección juvenil Las aventuras de Mío Cid, Autoedición.

Hernández Palacios, Antonio (2015), el Cid Integral, eeproducción y adaptación gráfica de Oriol Aleu, Carlos Oriondo y Amiran Reuveni, Barcelona, Ponent Mon [Reedición íntegra de la serie original publicada por el mismo autor entre 1971 y 1984].

ReED, Gary (guion) y Wayne ReID (dibujo) (2018). El Cid. Colección «Historia de España en viñetası. Cascaborra Ediciones [Traducción y reedición del original El Cid publicado en EE. UU. por Caliber Comics].

\section{Aparato crítico}

Abruzzese, Alberto (2004) «Cultura de masasi), Cuadernos de Información y Comunicación, 9, pp. 189-192.

Agullar, Dietris (2014), «El Cid en los medios: apropiación de la figura cidiana en los lenguajes de los siglos XX y XX|», Olivar, 15.22.

BECK, Lauren (2019), Illustrating El Cid, 1498 to Today. Montreal \& Kingston
/ London /Chicago, McGill-Queen's University Press.

Bolx Jovaní, Alfonso (2015), «Transmisión, pervivencia y evolución del mito cidiano en el heavy metalı, en Estudios de literatura medieval en la Península Ibérica, Carlos Alvar (ed.), San Millán de la Cogolla, Cilengua, pp. 303-315. Catalán, Diego (2000), la épica española. Nueva documentación y nueva evaluación, Madrid, Fundación Ramón Menéndez Pidal.

CRESPO-VILA, Raquel (2018), MMetaficción, intertextualidad y divulgación: El Cid, de José Luis Corrally, Castilla: estudios de literatura, 9, pp. 20-42. DOI: https://doi.org/10.24197/ cel.9.2018.20-42.

Cuñarro, Liber y José Enrique Finol (2013), «Semiótica del cómic: códigos y convencionesy, Signa. Revista de la asociación española de semiótica, 22, pp. 267-290. DOI: https://doi. org/10.5944/signa.vol22.2013.6353

Díez de Revenga, Francisco Javier (1993), "La Edad Media y la novela actual», Medievalismo: Boletín de la Sociedad Española de Estudios Medievales, 3, pp. 69-86.

Eco, Umberto (1996), "Hacia una "nueva Edad Media"l), La estrategia de la ilusión. Barcelona, Lumen, pp. 66-86.

Escandell Montiel, Daniel (2017), «Del Cid y la Zarramplana: el imaginario caballeresco español en los videojuegos»,, Monografías Aula Medieval, 6, pp. 109-123.

FletCHER, Richard (1989), El Cid, Madrid, Nerea.

Gallo León, Juan Pablo y M. Victoria Játiva Morales (2009), «La presencia de la Edad Media en el cómic»), en L'edat mitjana en el cinema i en la novel la histórica, Josep Lluís Martos Sánchez 
y Marinela García Sempere (coords.), Alicante, Institut Interuniversitari de Filologia Valenciana, pp. 231-254.

García, Santiago (2010), La novela gráfica, Bilbao, Astiberri.

Gómez Redondo, Fernando (1990), «La eclosión de lo medieval en la literaturan, Atlántida, 3, pp. 28-42.

Gutiérrez García-Huidobro, Julio (2014), «Nocilla Experience, la novela gráfica: adaptación y reescritura», Dicenda: Cuadernos de filología hispánica, 32 (Número Especial), pp. 189-204. DOI: $\quad$ https://doi.org/10.5209/rev_ DICE.2014.v32.44634

Heusch, Carlos (2017), «La construcción del mito cidiano», Cahiers d'études hispaniques médiévales, 40, pp. 155162.

Huertas Morales, Antonio (2015), La Edad Media contemporánea. Estudio de la novela española de tema medieval (1990-2012), Vigo, Academia del Hispanismo.

Lacarra, María Eugenia (1980), «La utilización del Cid de Menéndez Pidal en la ideología militar franquista», Ideologies \& Literature, 3, pp. 95-12.

MONTANER, Alberto (2007), Edición, prólogo y notas al Cantar de mio Cid, Barcelona, Círculo de LectoresGalaxia Gutenberg.

Peña Pérez, Francisco Javier (2010), «La sombra del Cid y de otros mitos medievales en el pensamiento franquista», Norba. Revista de Historia, 23, pp. 155-177.

Prieto Marugán, José (2007). El Cid y la música, Toledo, Ledoira.

RODIEK, Christoph (1990/1995), La recepción internacional del Cid: argumento recurrente, contexto, género, Madrid, Gredos.

Ruiz-DOMĖNeC, J. E. (2009), «El poder de la ficción: novela histórica y edad media», en La historia medieval hoy: percepción académica y percepción social, Navarra, Gobierno de Navarra, pp. 247-261.

Saguar García, Amaranta (2017), «Presencia del Cid en el Heavy Metal en relación al auge y al declive de algunos de sus subgénerosi, Monografías Aula Medieval, 6, pp. 7590.

SaItua, Iker (2018), «La enseñanza de la historia a través de la novela gráfica: una estrategia de aprendizaje emergentel», Revista de didácticas específicas, 18, pp. 65-87.

Salvador Miguel, Nicasio (1977), «Reflexiones sobre el episodio de Rachel y Vidas en el Cantar de Mio Cid»), Revista de filología española, LIX.1/4, pp. 183-224. DOI: https://doi. org/10.3989/rfe.1977.v59.i1/4.692

SpItzer, Leo (1962), «Sobre el carácter histórico del Poema de Mio Cid», en Sobre antigua poesía española, Buenos Aires, Universidad, pp. 9-25.

URIONDO, Carlos (2015), «El Cid de Antonio Hernández Palacios», en El Cid Integral, Antonio Hernández Palacios, Barcelona, Ponent Mont, pp. 3-8.

Vallejo, Irene (2019), El infinito en un junco. La invención de los libros en el mundo antiguo, Madrid, Siruela.

VARILLAs, Rubén (2009), La arquitectura de las viñetas. Texto y discurso en el cómic, Sevilla, Viaje a Bizancio Ediciones.

Yerro Villanueva, Tomás (2001), «Novela histórica española actual ambientada en la Edad Media: ensayo de aproximación», en Itinerarios medievales e identidad hispánica: XXVII Semana de Estudios Medievales, Pamplona, Gobierno de Navarra, pp. 221-256. 
CRespo-VILA, Raquel, «Del párrafo a la viñeta: El Cid (2020), de José Luis Corral y Alberto Delgadon, Storyca 3 (2021), pp. 39-54.

https://doi.org/10.51863/Storyca.2021.Crespo

\section{Resumen}

En línea con aquellos trabajos que ya dieron cuenta de la proyección de la materia cidiana sobre formatos o expresiones culturales ajenos al de la literatura —véase, por ejemplo: Rodiek ([1990] 1995), Aguilar (2014), Boix Jovaní (2015), Saguar García (2017), Escandell Montiel (2017)-, el propósito de este trabajo radica en el examen y comentario de la novela gráfica El Cid, aparecida en el año 2020, guionizada e ilustrada por Alberto Valero y basada en la novela histórica homónima de José Luis Corral, del año 2000. El objetivo es, pues, analizar esta nueva recreación de la historia de Rodrigo Díaz en relación con el texto originario del que parte -y aún con una larga tradición debida al héroe- y en función de las particularidades icono-textuales que atañen a la novela gráfica.

\section{Abstract}

Close to those works that already analyzed the projection of the Cidian matter on formats or cultural expressions other than literature - Rodiek ([1990] 1995), Aguilar (2014), Boix Jovaní (2015), Saguar García (2017), Escandell Montiel (2017)-, the aim of this article is to examine the graphic novel El Cid (2020), scripted and illustrated by Alberto Valero and based on the homonymous historical novel by José Luis Corral (2000). The objective is to analyze this new cidian recreation in relation to the original novel from which it starts, a long cidian tradition and the discursive particularities of the graphic novel.

\section{Palabras clave}

El Cid

Rodrigo Díaz de Vivar novela histórica actual novela gráfica José Luis Corral Alberto Valero

\section{KeyWords}

El Cid

Rodrigo Díaz de Vivar current historical novel graphic novel José Luis Corral Alberto Valero 